\title{
Untersuchungen über die durch die opsonische Reaktion hervorgerufenen Chemotropine.
}

\author{
Von
}

Prof. E. Centanni.

(Laboratorium für Allgemeine Pathologie an der königlichen Universität zu Siena.)

(Der Redaktion zugegangen am 6. Februar 1908.)

Daß die Opsonine in der Immunitätslehre Aufnahme gefunden, ist, wie bekannt, nicht etwa der Entdeckung einer neuen Tatsache zu verdanken, sondern einer neuen Auffassung der Erscheinung, die gewiß zu den am meisten untersuchten und besprochenen gehört, nämlich der Phagocytose. Die Streitfrage bezieht sich namentlich auf die Feststellung, ob das Immunserum, der Ansicht Metschnikoffs gemäß, als ein Stimulin auf die Leukocyten, oder, wie heutzutage behauptet wird, unmittelbar auf das Bakterium einwirkt.

Die erste Veranlassung zu der letzteren Annahme scheinen die von Denys und Leclef (1895) gemachten Beobachtungen gewesen zu sein. Diese Autoren bemerkten keinen wesentlichen Unterschied in bezug auf das phagocytäre Vermögen zwischen den Leukocyten eines gesunden und den Leukocyten eines immunisierten Tieres. Außerdem hatte ich schon 1901 hervorgehoben, daß der Pneumococcus durch den Kontakt mit dem entsprechenden Serum diesem sein Immunisierungsvermögen auf das Tier raubt, ohne beträchtlichem Schaden in seinen vegetativen und infektiösen Eigenschaften zu unterliegen. Die Grundzüge der heutigen Lehre waren somit im wesentlichsten schon entworfen. Hierauf haben Wright (1903) bezüglich der normalen und Neufeld und Rimpau (1904) bezüglich der immunisatorisch gewonnenen, die Phagocytose befördernden Substanzen des Blutes Versuche angestellt, bei welchen die drei Elemente, Serum, Keim und Leukocyt, welche die Reaktion abgeben, einzeln geprüft wurden, sodaß es diesen 
Forschern möglich wurde, die Rolle eines jeden dieser Elemente nachzuweisen und infolgedessen eine sichere Lehre auf das Prinzip zu gründen, daß das Opsonin ein Antikörper des Bakteriums ist und die Phagocytose nur eine, bei einem schon vorbereiteten Keime auftretende Erscheinung darstellt. Dieses Prinzip darf heute, infolge der zahlreichen diesbezüglichen Untersuchungen, welche die schon umfangreiche Literatur aufzuweisen hat, als endgültig festgesetzt werden. Einige Fragen sind jedoch auf diesem Gebiete noch nicht erörtert.

Ich habe meine Aufmerksamkeit auf eine Phase gerichtet, welche auf die bisher vorzugsweise beobachtete folgt; ich habe nämlich die Erscheinungen untersucht, die nach geschehener Fixierung des Opsonins von seiten des Bakteriums auftreten, und dabei festzustellen versucht, auf welche Weise die Phagocytose dabei zustande kommt.

Auf Grund der allgemeinen Lehre des Tropismus, laut welcher die beweglichen Organismen unter dem Einfluß bestimmter Kräfte (chemischer, thermischer, elektrischer usw.) sich orientieren, müssen wir annehmen, daß, infolge der Berührung mit dem Opsonin, das Bakterium eine positive chemotropische Substanz erzeugt und an die Umgebung abgibt, welcher die Fähigkeit zukommt, die amöboide, aufnehmende Tätigkeit der Leukocyten, die ihrem Einfluß ausgesetzt werden, zu reizen und anzuregen.

Demnach tritt das Chemotropin, in der Opsoninlehre, als das direkte Agens der Phagocytose auf; aus diesem Grunde eben ist es interessant, dasselbe direkt zum Gegenstand eines eingehenden Studiums zu machen. Die vorliegenden Untersuchungen, die eben darauf gerichtet sind, und zu welchen der Pneumococcus das Versuchsmaterial liefert, hängen mit meiner früher erschienenen Arbeit über den Aderlaß zusammen, insofern die Methode und das Material zum Teile den beiden Arbeiten gemeinsam ist.

Das opsoninhaltige Serum wurde denn auch größtenteils aus Kaninchen gewonnen, die dazu verwendet worden waren, das Immunisierungsvermögen des Blutserums von an Pneumonie erkrankten Menschen zu prüfen, und die nach einer lo- 
kalen Reaktion die Krankheit überstanden hatten; dieser lokale Herd ist, wie ich bewiesen habe, eine ungemein reiche Quelle von Immunsubstanzen, und deren Resorption verleiht dem Serum des Tieres ein sehr hohes opsonisches Vermögen. Manchmal wurde das Serum aus Menschen gewonnen, welche die Pneumonie überstanden hatten und sich im Stadium der Rekonvalescenz befanden; manchmal aus Hunden und Schafen, die mit im Äther sterilisierten Kulturen immunisiert worden waren, weil diesen Kulturen, meinen schon längst gemachten Beobachtungen entsprechend, die Eigenschaft zukommt, die aktiven Elemente des Impfstoffes im höchsten Grade wirksam zu erhalten. Um bei den Prüfungen die erforderliche Empfindlichkeit $z u$ erzielen, wurde das Limitvermögen für jedes Serum im voraus, die Minimaldosis festgestellt, die zur Hervorrufung einer ausgesprochenen Phagocytose nötig war, nämlich bei frischen Seren durchschnittlich $1: 50-100$.

Die Beurteilung beruht bei diesen Versuchen hauptsächlich auf folgenden zwei analytischen Verfahren: Phagocytose in vitro nach Wright und Chemotaxis in den subkutanen Kapillarröhrchen nach Pfeffer.

Bei der Prüfung der Phagocytose verfuhr man folgendermaßen. Von opsoninhaltigem, natürlichem oder verdünntem Serum wurden $0,25 \mathrm{ccm}$, von Leukocyten aus dem Blute eines Tieres der gleichen Rasse 0,05, von Pneumococcus in Blutkultur eine Öse von 2,5 mm Durchmesser genommen. Aufenthalt in $38^{\circ}$ warmem Wasser mit zwei Prüfungen, nach 15 und nach 25 Minuten; die zweite Prüfung dient als Kontrolle für die erste und ist geeignet, ohne außerhalb der richtigen Periode zu sein, die Tätigkeit trägerer Sera an den Tag zu bringen. Die Präparate wurden durch 10' im Methylalkohol, vorzugsweise aber bei $120^{\circ}$ Wärme fixiert, weil auf diese Weise das Präparat klarer bleibt und die Leukocyten einzelner'Tiere leichter gefärbt werden, was bei dem Kaninchen der Fall ist, bei dem das Protoplasma eine deutliche rosige Farbe annimmt, auf we!cher die Keime noch deutlicher abstechen. Der phagocytäre Index wird durch Zählung von 50 polynukleären Leukocyten für jedes Präparat berechnet. 
Mit den Kapillarröhrchen habe ich unter Berücksichtigung folgender Vorsichtsmaßregeln gearbeitet. Verschluß des einen Endes, um Verschiebungen der Säule vorzubeugen; beträchtliche Länge, nicht unter $3 \mathrm{~cm}$; Einführung mit der Mündung in die Tiefe der Wunde, um dem Einfluß der im Bereiche des Hautschnittes sich vollziehenden Reaktion zu entgehen; Anwendung einer beträchtlichen Anzahl bei jeder Prüfung - ein Bündel von etwa 10-12 Stück - und Anstellung der verschiedenen Proben derselben Serie, bei demselben Tiere an verschiedenen Stellen des Rückens, um die Resultate miteinander vergleichen zu können. Die Röhrchen werden im Durchschnitt 20 Stunden stehen gelassen; zur Beurteilung der Resultate dient die Tiefe, bis zu der die Leukocyten vorgedrungen sind, und die Dichte ihrer Anhäufung, d. h. ob ununterbrochene Pfröpfe, Flocken oder bloß einzelne Elemente zu sehen sind.

Infolge der Mannigfaltigkeit der mitwirkenden Faktoren und der äußerst großen Empfindlichkeit der an diesen Prüfungen beteiligten Reagenzien schwanken die Resultate unter den geringsten Einflüssen. Die mittels Kapillarröhrchen vorgenommenen Prüfungen können, wenn sie unter Beobachtung obenerwähnter Maßregeln angestellt werden, bedeutungsvolle, miteinander über- einstimmende Resultate liefern. Im Gegensatze dazu unterliegen die Versuche nach Wright, wie manche Forscher ausdrücklich bemerken, sehr erheblichen Schwankungen, und soll man daher die Durchschnittszahlen von verschiedenen Prüfungen nehmen.

Außer der strengsten Beobachtung der Verhältnisse der Menge, sowie der Zeit und der Temperatur, ist dabei die am wichtigsten zu beobachtende Vorsichtsmaßregel, den Behauptungen sämtlicher Autoren gemäß, die Anwendung möglichst frischer, nicht über zwei Tage alter Materialien.

Diese erste Serie von Untersuchungen habe ich zum Zwecke vorgenommen, namentlich folgende Hauptpunkte in der $\mathrm{zu}$ erörternden Frage ins klare zu bringen: Wie kommt das Chemotropin zustande 'und wie diffundiert es? Welches sind die Bestandteile desselben? Welche Veränderungen werden an den durch dasselbe beeinflußten Leukocyten hervorgerufen? 
Weitere Untersuchungen werden später noch mehr Lichtt auf einige noch nicht erörterte Fragen werfen, und zwar namentlich in bezug auf die physikalischen und chemischen Eigenschaften sowohl, als auch auf die biologischen, die infolge derr Einspritzung in den lebenden Organismus zur Geltung kommen..

\section{Kombinierung des Opsonins mit dem Bakterienrezeptor.}

Es ist das die erste Phase, die das Instandekommen des; Chemotropins einleitet, und dieselbe sollte eigentlich durch die; Untersuchungen über die Opsonine zur Genüge bekannt sein. Es ist darum zu verwundern, daß sowohl Wright als auch seine Mitarbeiter bei den ersten Untersuchungen, die zur Begründung dieser Lehre führten, zur Feststellung dieser Kombinierung nicht etwa das klassische Verfahren der elektiven $\mathrm{Ab}$ sorption benutzten, sondern eine Reihe indirekter Beweise herangezogen haben, so z. B. die Unschädlichkeit der Erhitzung auf $60^{\circ}$ nach vorangegangener Kombinierung des normalen Opsonins mit dem Bakterium, das Ausbleiben einer Veränderung in dem phagocytären Vermögen der Leukocyten gegen anorganische Teilchen nach Inaktivierung des Serums, die Möglichkeit, die Leukocyten zweier mit verschiedenem Vermögen ausgestatteten Blutproben, nicht aber deren Sera zu ersetzen. Neufeld und Rimpau haben im Gegenteil bei den Immunopsoninen das Verfahren der elektiven Absorption direkt angewandt, und dieselbe Methode wurde nachher von mehreren englischen Forschern benutzt (Bulloch mit Atkin und mit Western, Dean, Hektoen und Rüdinger, Leishman).

Bei beiden Proben der geschehenen Absorption, und zwar sowohl betreffs der Verringerung des Serumvermögens infolge des Kontaktes mit den Bakterien, als auch in betreff der danach erworbenen Eigenschaften seitens der gewaschenen Keime, erzielte man positive Erfolge, die jedoch nicht so ausgesprochen und scharf waren wie die an derselben Methode bezüglich anderer Immunsubstanzen erhaltenen Resultate. Der Grund dieser Tatsache wird bald im folgenden erörtert.

Zunächst müssen in bezug auf unsere Versuche einzelne Umstände berücksichtigt werden, die sich bei der Absorption 
geltend machen, wie das aus den bisherigen Beobachtungen. hervorgeht. So läßt sich aus der einige Minuten nach Anstellung der Prüfung eifrig vor sich gehenden Phagocytose schließen, daß die Kombinierung mit der größten Raschheit erfolgt. . Es ist ferner nachgewiesen, daß in Übereinstimmung mit dem Gesetz der Gemeinschaft der Rezeptoren ein jedes Opsonin sich besser, aber nicht ausschließlich (Centanni, Farland und L'engle), mit dem entsprechenden Keim kombiniert; daß die Kombinierung selbst bei $0^{0}$, wenn auch vielleicht nicht mit der gleichen Lebhaftigkeit eintritt; daß selbst die abgetöteten Bakterien und zwar bei einer $115^{\circ}$ hohen Temperatur ihre Empfindlichkeit dem Serum gegenüber beibehalten.

\section{2. Über die Schnelligkeit, mit welcher das Chemotropin abgegeben wird.}

Auf die Kombinierung des Opsonins mit dem Bakterium folgt eine Phase, in welcher das erzeugte Produkt löslich wird und austritt; die Schnelligkeit, mit welcher die beiden Phasen aufeinander folgen, läßt sich abmessen.

$\mathrm{Zu}$ diesem $\mathrm{Zwecke}$ werden Prüfungen angestellt, bei welchen

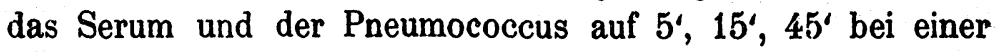
Temperatur von $25^{\circ}$ in Berührung kommen. Darauf werden die Bakterien dreimal unter Abzentrifugierung gewaschen und jede Probe wird, nachdem die Aufschwemmung abzentrifugiert worden, in zwei gleiche Hälften geteilt. Die Phagocytose wird bei den so behandelten Bakterien in der Weise festgestellt, daß man für die eine Serie Kochsalzlösung, für die andere aber aktives opsoninhaltiges Serum anwendet.

Sensibilisierte Pneumococcen $5^{\prime}\left\{\begin{array}{l}\text { ungewaschen }- \text { zahllos } \\ \text { gewaschen }\left\{\begin{array}{l}\text { Kochsalzlösung }-7 \\ \text { opsoninhalt. Ser. }- \text { zahllos. }\end{array}\right.\end{array}\right.$
,$\quad 15^{\prime}$ gewaschen, Kochsalzlösung - 11.
,$\quad 45^{\prime}\left\{\begin{array}{l}\text { ungewaschen - zahllos } \\ \text { gewaschen }\left\{\begin{array}{l}\text { Kochsalzlösung }-9 \\ \text { opsoninhalt. Ser. }- \text { zahllos, }\end{array}\right.\end{array}\right.$

Kontrolle (normale Keime) $\left\{\begin{array}{l}\text { in Kochsalzlös.(spontane Phagocytose) }-2 \\ \text { in opsoninh. Ser. }-55 .\end{array}\right.$

Der Übergang von der Kombinierung mit dem Opsonin zur Abgabe des löslichen Chemotropins vollzieht sich demnach 
im Bakterium mit der größten Raschheit. Schon nach einem 5 Minuten langen Kontakte mit dem Serum bleibt nach dem Waschen im Bakterium eine äußerst partielle Sensibilisierung zurück, die fast unverändert bleibt, nachdem der Kontakt bei Zimmertemperatur auf $45^{\prime}$ verlängert wird. Es muß jedoch hervorgehoben werden, daß, wenn das Bakterium wieder mit aktivem Serum in Berührung gebracht wird, dasselbe von neuem Chemotropin abgibt.

In ähnlicher Weise wurde ferner eine Reihe von Versuchen angestellt, bei welchen man das Material durch 15 Minuten bezw. durch 2 bis 8 Stunden im Brutschrank stehen ließ; dabei kam die beschleunigende Wirkung der Wärme auf die Reaktion, noch mehr aber die Zunahme der Keime in Betracht. Nach dem Aufenthalt von 2, bezw. 8 Stunden war der Umstand sehr deutlich zu erkennen, daß die Keime, selbst wenn sie das Waschen nicht erfahren hatten, ihre nach 15 Minuten sehr ausgesprochene Sensibilisierung eingebüßt hatten.

$\mathrm{DaB}$ das Ausbleiben der Phagocytose einer eventuellen schädlichen Wirkung auf die Leukocyten von seiten der lösbaren Produkte der Kultur nicht zuzuschreiben ist, wird im folgenden bewiesen. Wir müssen also annehmen, daß das Chemotropin, welches der in dem angewendeten Serum vorhandenen Opsoninmenge entsprechend vom Bakterium erzeugt worden war, nach jener Zeit schon vollständig ausgeschieden worden, ja, die Keime haben um diese Zeit normale Rezeptoren wieder erzeugt, da sie unter Zuführung frischen Opsonins eine lebhafte Phagocytose hervorrufen.

Weitere Versuche nach demselben Typus wurden wieder mit aus Hunden gewonnenem Material angestellt, das eine äußerst lebhafte Aktivität aufwies; obwohl nach dem Waschen eine deutlich zu erkennende Verringerung der Sensibilisierung auftritt, bleibt diese auch nach $45^{\prime}$ noch immer beträchtlich. Demnach erscheint die Dauer der auf das Bakterium ausgeübten Wirkung als von dem Serumvermögen und der Empfindlichkeit der Leukocyten abhängig.

Bei diesen Versuchen macht sich gelegentlich, in bezug auf die Agglutinine, eine ähnliche Erscheinung geltend, wie sie 
bezüglich der Opsonine wahrgenommen wurde, nämlich, daß Keime, die in dem Immunserum als ansehnliche Flocken auftreten, nach erfolgtem Waschen und nach Aufschwemmung in Kochsalzlösung wieder auseinander gehen und dann gleichmäßig verteilt erscheinen.

In der von dem sensibilierten Bakterium erlittenen, raschen Einbuße liegt gewiß die nächste Ursache der Schwierigkeit, welche die Forscher bei der methodischen Anwendung der oben erwähnten elektiven Absorption getroffen haben. Einzelne Forscher liefern einen direkten ziffernmäßigen Nachweis dieser Schwankungen. So heben Hektoen und Rüdinger hervor, daß, während der Staphilococcus und der Streptococcus, wenn sie im aktiven Serum belassen werden, den Index 22,0 resp. 22,2 abgeben, der Index nach erfolgtem Waschen auf 10,0 resp. 14,0 sinkt. Diese Verringerung wird von diesen Autoren dem Umstande zugeschrieben, daß ein Teil der Bakterien beim Waschen verloren geht; es ist bekannt, wie stark die Schwankungen in der Anzahl der angewandten Keime das Resultat der Prüfung beeinflussen. Nun darf aber eine Einbuße an Keimen bei der Abzentrifugierung nicht allzu hoch eingeschätzt werden, da es sich hier meist um agglutinierte Keime handelt, die sich leicht absetzen. Bei unserem Versuche blieb ein solcher Einwand ganz ausgeschlossen, da wir die gleiche nach der Abzentrifugierung verteilte Anzahl Keime angewendet haben.

\section{Dauer der Ausscheidung von Chemotropin.}

Die oben erwähnte Tatsache, daß der Keim, der durch Waschen nach dem ersten Kontakte mit dem opsoninhaltigen Serum seinen ganzen Chemotropingehalt verloren hatte, nach einem neuen Kontakt mit frischem Serum wieder frisches Chemotropin erzeugt, veranlaßte uns, nachzuforschen, wie weit diese abwechselnde Fähigkeit des Bakteriums getrieben werden kann; umsomehr, da die Opsonine als solche die Lebensfähigkeit des beeinflußten Keims nicht $\mathrm{zu}$ beeinträchtigen scheinen.

$\mathrm{Zu}$ diesem $\mathrm{Zwecke}$ wollten wir unter wiederholtem Sensibilisieren und folgendem Waschen des Keims feststellen, wie lange einerseits der Keim die Fähigkeit beibehält, der Phago- 
cytose zu verfallen, bezw. wie lange aktives Chemotropin in der Flüssigkeit auftritt. Dabei muß ganz besonders darauf geachtet werden, daß der Keim nicht in den Stand gesetzt wird, weiter zu vegetieren und somit seine Einbuße nach und nach zu ersetzen. Darum habe ich im Laufe des Versuches eine niedrige Temperatur benutzt, ferner abgetötete Keime angewendet.

Bei den Versuchen der ersten Reihe blieb die Temperatur bei $16-18^{\circ}$; nach jeweiligem 3 stündigen Kontakt wurden die Bakterien wiederholt gewaschen, wobei die zusammenlaufenden Flocken durch eine dünne Pipette möglichst getrennt und auseinander gebracht wurden. In einem der Röhrchen wurde unter Zuführung von Leukocyten die Phagocytose direkt geprüft, in den übrigen wurde immer neues Serum bis zur weitgehendsten Erschöpfung hinzugesetzt.

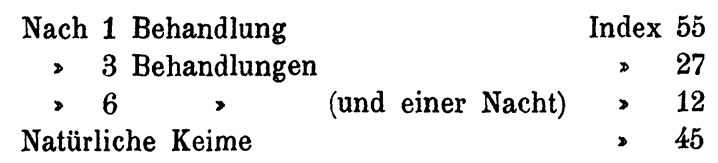

Der Kontrolle gegenüber scheint bei den ersten Immersionen der Index eine Erhöhung erfahren zu haben, und zwar anscheinend, weil der dreistündige Aufenthalt des Keimes im Serum die Wirkung des Opsonins auf denselben tiefgehender gestaltete. Nach wiederholten Behandlungen mit dem Serum erscheint eine Tendenz zur Erschöpfung, aber letztere scheint nicht vollständig $\mathrm{zu}$ sein, was wohl dem Auftreten des ursprünglichen Chemotropins des Bakteriums, von dem später die Rede sein wird, oder aber einer bei der niederen Temperatur zu langsam erfolgenden Reaktion, oder einer partiellen Wiederherstellung der letzten Rezeptoren zugeschrieben werden darf.

Unter dem Mikroskope erscheinen diese erschöpften Keime als ziemlich wohlerhalten, sie weisen jedoch eine geringere Färbbarkeit und schärfere Umrisse auf. Um sie auf ihre Lebensfähigkeit hin zu prüfen, braucht man sie nur in normales Kaninchenserum zu bringen. Nach 10 Stunden ist die Kultur schon reichhaltig, und eine Prüfung mit opsoninhaltigem Serum und Leukocyten zeigt eine ebenso starke Phagocytose wie bei nor- 
malen Keimen. Der Keim ist dann, naeh möglichst gründlicher Entfernung des auf Opsonin reagierenden Bestandteiles, noch der Vermehrung fähig und erzeugt nach kurzer Zeit die opsonophile Schicht.

Diese Beobachtungen sind einem engen Zusammenhang mit der Veränderung, die man als tierische Bacillen (Bail) bezeichnet hat, bei welcher ein Bakterium, das aus den Kulturen entnommen und gegen Immunkörper empfindlich ist, durch den Aufenthalt in dem immunisierten Tiere diese Eigenschaft einbüßt und infolge dieser Anpassung, die selbst wenige Stunden nach erfolgter Infektion auftritt, den Immunzustand überwindet und den Tod des Tieres verursacht. Auf diesen Umstand ist hauptsächlich der Mißerfolg in vivo bei Seren, die sich in vitro als wirksam erwiesen hatten, zurückzuführen.

Bei den zur Erschöpfung des Chemotropins mittels abgetöteter Keime vorgenommenen Versuchen stößt man auf den. mißlichen Umstand der verminderten Färbbarkeit bei dem auf verschiedene Weisen (Wärme, Äther, Altwerden usw.) abgetöten Pneumococcus. An Kulturen, welche durch halbstündigen Aufenthalt bei $58^{\circ}$ abgetötet wurden, habe ich nachweisen können, daß nach der Abtötung dieses Keimes die opsonophilen Rezeptoren ihre Tätigkeit beibehalten, sodaß der Kontakt mit Serum eine lebhafte Phagocytose hervorruft, die den Keimen allein abgeht.

Angesichts dieser Schwierigkeit, welcher man bei der Beobachtung der Präparate begegnet, habe ich Untersuchungen nach einer anderen Richtung hin angestellt, nämlich ich habe die Veränderung zu bestimmen versucht, die das chemotaktische Vermögen der entfernten Sera bei den successiven Kontakten erfuhr. $\mathrm{Zu}$ diesem Zwecke wurde der Bodensatz einer durch Altwerden (3-5 Tage) sterilisierten Kultur in Bouillon und Blut mit einer etwa zehnfachen Menge opsonischen Serums vermengt, dann jede Probe auf eine Stunde in den Brutschrank gelassen; das wieder abgetrennte Serum wird zu der Prüfung mittels Kapillarröhrchen verwendet.

Serum nach 1 Behandlung Tiefe: $3,7 \mathrm{~mm}$, Dichte: starke

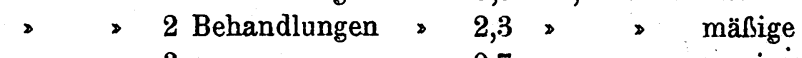

$>>3>0,7>$ wenige. 
Die Erzeugung von Chemotropin scheint bei Anwendung toter Keime infolge wiederholter Kontakte schneller zu Ende zu gehen, als es bei lebendigen Keimen der Fall ist; es muß nun festgestellt werden, ob die Wärme einen Teil der opsonophilen Elemente inaktiviert, oder ob das Bakterium unter diesen Umständen das erzeugte Chemotropin rascher abgibt.

Aus sämtlichen Untersuchungen geht hervor, daß der Pneumococcus eine beträchtliche Menge opsonophiler Komplexe besitzt, welche sich nach und nach in verschiedenen Phasen mit dem Opsonin kombinieren, als seien gleichsam verschiedene Arten von Rezeptoren, die eine stufenweise abnehmende Avidität aufweisen, vorhanden, oder vielmehr, als wären diese Komplexe schichtenweise angeordnet und so, daß sie an der Peripherie gleichsam eine molekuläre Umhüllung bildeten; eine solche Voraussetzung ist mit der Raschheit der Opsonophilen zu reagieren und mit der Unschädlichkeit ihrer Entfernung für den Keim im Einklang.

\section{Verhältnis zwischen der opsonophilen und der endotoxischen Zone des Bakteriums.}

Die Forschungen über die Chemotropin erzeugenden Substanzen sind geeignet, eine Erweiterung der Kenntnisse über die Beschaffenheit des Bakteriums herbeizuführen, welches, ebenso gut wie jede andere Zelle, eine hoch komplizierte Beschaffenheit aufweist; ebenfalls, wie im Bereiche der Chemie die Anzahl der durch die Analyse aufgefundenen Bestandteile zunimmt, so wird durch die Immunitätslehre eine immer größere Anzahl Antikörper nachgewiesen, die von einem und demselben Keime hervorgebracht werden können.

Dazu ist es erforderlich, eine weitere Eigenschaft der opsonophilen Pneumococcensubstanzen ins Auge zu fassen, nänlich deren Unschädlichkeit. Zu dieser Untersuchung können die Filtrate von Kulturen in Bouillon und Blut, vorzugsweise aber in Kaninchenserum benutzt werden; diese Filtrate wiesen bei den Prüfungen, in bezug auf die Opsoninerzeugung im Organismus, als auch auf die später zu besprechende Neutralisierungsfähigkeit in vitro einen reichlichen Gehalt von solchen 
opsonophilen Substanzen auf. Der dazu verwendete Keim entstammt aus typischen Fällen kruppöser Pneumonie, hat verschiedene Passagen durch Kaninchen erfahren und ist in den Zeiträumen zwischen den Passagen jedesmal in frischem Kaninchenblut gezüchtet worden.

Die Unschädlichkeit ergibt sich zunächst in bezug auf die Leukocyten bei den Prüfungen in vitro, bei welchen diese Kulturflüssigkeiten die phagocytäre Tätigkeit der Leukocyten, die darin gestanden haben, vollständig intakt lassen, sodaß, wenn bei der $\mathrm{W}$ rightschen Probe diese Flüssigkeiten in der ersten Periode, wo ihre Kombinierung mit dem Opsonin noch nicht erfolgt ist, hinzugesetzt werden, die Phagocytose ebensowenig beeinträchtigen, wie wenn Kochsalzlösung beigemengt worden wäre.

Die gleiche Unschädlichkeit kann auch in vivo nachgewiesen werden, da die benannte Flüssigkeit, selbst in einer Menge von $10 \mathrm{ccm}$ pro Kilogramm dem Kaninchen intravenös injiziert werden kann, ohne daß sie allein eine schädliche Wirkung hervorruft, noch eine schon entwickelte Infektion befördert. Selbst bei Menschen ist nach mehrmals vorgenommenen subkutanen Injektionen von 50-100 ecm (Mancini) nie eine noch so geringe Reaktion eingetreten, und zwar weder an der Stelle der Injektion, noch eine Allgemeinreaktion, während jedoch in kurzer Zeit ein hohes Immunitätsvermögen im Blute hervorgerufen wurde.

Diese Wahrnehmung hatte ich hauptsächlich vor Augen, als ich zu einer Zeit, da alle Erseheinungen auf die Toxine zurückgeführt waren, auf Grund meiner ersten Versuche (1895) das Vorhandensein von Immunsubstanzen, die weder toxinhaltig, noch toxischen Ursprungs waren, entschieden verfocht. Die opsonophile Schicht des Bakteriums besitzt eine geringe, die Immunität anregende Wirksamkeit, wie sie bei einfach heterogenen Protoplasmen nachgewiesen ist und regt höchst wahrscheinlich dieselben Apparate für normale Ernährungsfunktion zur Tätigkeit an.

Im Gegensatz zu diesen Eigenschaften des opsonophilen Bestandteiles des Bakteriumkörpers steht dessen endotoxischer Bestandteil mit seinen toxischen- Eigenschaften und seiner topo- 
graphisch tieferen Lage. Bezüglich der Toxicität des Pneumococcus waren die Meinungen geteilt. Eine gewisse Toxicität erweist sich schon bei den Prüfungen in vitro auf die Phagocytose, die bekanntlich nur schwerlich über die erste halbe Stunde hinaus fortgesetzt werden können, weil sich dann die vorhandenen Keime auflösen und die Leukocyten einem weitgreifenden Degenerationsprozeß unterliegen. Solche Erscheinungen sind im Laufe der Pneumococceninfektion im Blute in reichlichem Maße zu beobachten.

Die Schwierigkeit, aus der Kulturflüssigkeit aktives Toxin zu gewinnen, ist auf den Umstand zurückzuführen, daß die äußere Bakterienhülle für solche Substanzen schwer durchgängig ist, oder dieselben erst durchläßt, wenn sie infolge der Autolyse in Zersetzung übergegangen sind. Wenn man frische Keime, die durch den Kontakt mit der flüssigen Luft ihre Zähigkeit eingebüßt haben, zersprengt, wie das von Mac Fadyen angeführt wurde, kann bei diesem Keime ein sehr hohes toxisches Vermögen nachgewiesen werden.

Ich habe solche Produkte durch 4-6 stündiges Zerreiben von Kultur mit Quarzpulver vermengt erhalten. Dieses Extrakt vermag in vitro einen viel rascheren Zerfall der eingeführten Leukocyten hervorzurufen, als er nach Aufenthalt in dem opsonophilen Extrakte wahrgenommen wird. Es wird ferner beobachtet, daß, wenn man dieses endotoxische Material mit Serum, welches durch die mittels der gewöhnlichen Kulturflüssigkeit vorgenommene Schutzimpfung gewonnen wurde, in Berührung bringt, dasselbe kein diese Kategorie von Produkten neutralisierendes Antitoxin aufweist.

Nach sämtlichen hier angeführten Beobachtungen ist das Opsonin aufzufassen als ein spezifischer Antikörper für die peripherischen Bestandteile des Bakteriums, die am leichtesten gelöst werden und bei der Schutzimpfung ihre Wirksamkeit ausüben. Das Opsonin kann also als ein partielles Bakteriolysin, als ein Esolysin aufgefaßt werden, während bei den eigentlichen Bakteriolysinen das Vorhandensein eines Endolysins anzunehmen ist, zu dem oft auch ein Esolysin hinzukommt, wie das durch das gleichzeitige Erscheinen selbst von Opsoninen bei Bakterien, die 
am meisten eine Lysis erfahren wie z. B. Vibrionen, bewiesen ist. Der Gegensatz zwischen Metschnikoffs und Pfeiffers Auffassung mochte unausgleichbar erscheinen, solange der $\mathrm{Be}$ griff von der Anzahl und der Beschaffenheit der in einem und demselben Bakterium erzeugbaren Antikörper noch sehr unbestimmt und mangelhaft war.

\section{Versuche über Opsonoide.}

Die Einbuße an Empfindlichkeit und die Unfähigkeit, die chemotropische Umwandlung der Opsonine weiter zu treiben, welche, wie wir gesehen haben, die Bakterienzelle infolge der Ausscheidung ihrer opsonophilen Komplexe erfährt, ist ein glänzendes Beispiel, das zur Stütze der von mir verfochtenen Auffassung der Zellenstomose dient, nämlich, daß der Zelle infolge der Entfernung der spezifischen, gesättigten, kombinierenden Komplexe ihre Empfindlichkeit abgeht. Der Stomoselehre kommt eine sehr bestimmte Stelle-in der Geschichte der Immunität $\mathrm{zu}$, da sie deutlich formuliert und nachgewiesen worden war (1893), als die Theorie der Seitenketten in die Immunitätslehre eingeführt wurde (1897), welche eine spätere Phase der Stomose, die Hyperproduktion der gesättigten Komplexe, erörtert. Die Stomose ist in der Tat keine Hypothese, sondern eine an der Hand direkter Prüfungen sowohl in vivo, als in vitro nachweisbare Tatsache. Gegenwärtig nimmt sie eine ganz besonders hervorragende Rolle ein, seitdem nicht nur in der allgemeinen Biologie für die Anpassung der Organismen an die Umgebung, sondern auch auf dem Gebiete der Immunität nachgewiesen wurde, daß die Veränderungen der cellulären Empfindlichkeit verbreiteter sind, als die zeitweiligen und nebenseitlichen Veränderungen, die in den Säften vorkommen. (Anpassungsimmunität: Sauerbeck, Eisenberg, Wassermann und Citron).

Einen weiteren Beitrag zu dieser Lehre habe ich zu liefern gesucht, indem ich versuchte festzustellen, ob die Stomose in einer anderen Form, nämlich durch einfache Sättigung ohne Entfernung, hier Anwendung finden könnte, wie ich sie bei speziellen Untersuchungen hatte nachweisen können. Dies läßt 
sich erreichen mit dem Abschwächungsprodukte des Opsonins, dem Opsonoid, das sich mit dem opsonophilen Molekül ohne Hervorrufung der Lysis kombiniert, infolgedessen das Bakterium nicht etwa, wie wir uns bei der Wirkung des aktiven Opsonins vorstellen können, eine Art Abschälung erfährt, sondern vielmehr gleichsam einen unangreifbaren Anstrich bekommt.

Ich habe Sera von Kaninchen, von Hunden oder von Menschen benutzt, die durch den Aufenthalt bei Sommertemperatur 1-3 Monate lang abgeschwächt worden waren. Ein Teil derselben wurde ohne weiteres geprüft, das übrige wurde vorher noch durch eine halbe Stunde bei $64-65^{\circ}$ abgeschwächt. Der Kontakt mit den Keimen dauerte von 8 Stunden bis 2 Tage bei $16-18^{\circ}$, wobei starke Serumdosen angewendet wurden. Nach erfolgtem Waschen wurden zweierlei Prüfungen zur Zeitstellung der Phagocytose vorgenommen: bei der einen wurde aktives opsoninhaltiges Serum, bei der anderen aber nur Kochsalzlösung hinzugesetzt, um festzustellen, ob die abgeschwächten Keime allein noch einige Tätigkeit aufzuweisen vermochten.

Aus allen Prüfungen ging hervor, daß selbst nach der Einwirkung der Wärme ein Rest der opsonischen Tätigkeit noch vorhanden ist, die infolge des längeren Kontaktes zur Geltung kommt. Jedenfalls vermag das frische opsonische Serum noch immer von diesen Bakterien fixiert zu werden, denen es eine Fähigkeit zur Phagocytose verleiht, welche derjenigen bei normalen Keimen nachweisbaren gleichkommt oder dieselbe gar übersteigt. Sei es nun kraft dieser etwas schwierigen Bildung typischer Opsonoide, oder infolge einer Verdrängung der mit geringerer Avidität verankerten Opsonoide, Tatsache ist, daß es unter den gegebenen Verhältnissen nicht möglich gewesen ist, diese Form der cellulären Stomose nachzuweisen.

\section{Beschaffenheit der chemotropinogenen Bestandteile des Bakteriums.}

Die Feststellung der Beschaffenheit und der Eigenschaften desjenigen unter den Bestandteilen der Bakterienzelle, welcher zur Erzeugung des Chemotropins dient, ist vor allem insofern interessant, als sie zur Lösung einer grundlegenden Frage über 
das Wesen des Chemotropins beiträgt. Wir dürfen nämlich das Chemotropin nicht einfach als das direkte Erzeugnis der Verbindung zwischen der opsonophilen Substanz des Bakteriums und dem Serumopsonin ansehen, sondern wir müssen mit der Möglichkeit rechnen, daß dasselbe auch dem Auftreten eines dritten, selbständigen Bestandteiles zuzuschreiben sein könnte, welch letzterer auf indirektem Wege infolge der opsonischen Wirkung von der Zelle freigegeben wird, nämlich wie das Hämoglobin nach der Verbindung des Hämolysins mit dem im Stroma befindlichen Receptor frei wird.

Trachten wir zunächst zu bestimmen, ob diese opsonophilen Bestandteile von dem Bakterium losgelöst werden können und unter welchen Umständen sie frei in der Flüssigkeit zu erhalten sind. Der Anhaltspunkt zum Nachweise dieser Elemente ist deren spezifische Tätigkeit, das Opsonin zu neutralisieren, so daß die zu prüfende Flüssigkeit die Fähigkeit verliert, die in Berührung gebrachten Keime für die Phagocytose zu präparieren. Ich habe die Prüfung an Pneumococcenkulturen, die im Kaninchenserum oder in einer Mischung von Bouillon und Blut angelegt worden waren, in der Weise vorgenommen, da $B$ ich den flüssigen Teil durch Filtration mittels Tonfilter absonderte und denselben mit der gleichen Menge opsoninhaltigen Serums mischte. Da aus den früheren Versuchen hervorging, daß der Keim infolge des Waschens seine Sensibilisierung einbüßt, so wurde bei diesem Versuche die Mișchung von Serum mit in der Reaktion begriffenem Filtrat nicht entfernt. Prüfung mit dem Filtrat der Kultur in Kaninchenserum.

Prüfung der frisch hergestellten Mischung:

Serum 1:5 in Kochsalzlösung verdünnt -32

> $1: 5$. Kulturfiltrat,-45 .

Prüfung der Mischung nach 15 Stunden:

Serum mit Kochsalzlösung verdünnt - zahllos

$\triangleright$ Kulturfiltrat $\searrow-8$.

Aus dem Versuche geht hervor, daß in der Flüssigkeit der gewöhnlichen Kulturen ein Bestandteil aufgelöst ist, welchem die Fähigkeit zukommt, das Opsonin zu neutralisieren; nur kommt diese Wirkung erst nach einem mehrstündigen Kontakte

Hoppe-Seyler's Zeitschrift f. physiol. Chemie. LV. 
mit dem Serum zur Geltung, was anscheinend dafür zeugt, daß die opsonophilen Substanzen bei ihrer Trennung vom Bakterium etwas von ihrer Avidität einbüßen. Daß ferner in der ersten Periode des Kontaktes die Phagocytose trotz des zugesetzten Filtrates in intensiver Weise auftritt, bestätigt die Unschädlichkeit dieses opsonophilen Materials den Leukocyten gegenüber, und begegnet dem Einwande, daß die in der folgenden Periode auftretende Hemmung auf diesen Umstand zurückzuführen sei.

Aus diesem Versuche geht jedoch noch nicht hervor, ob die auf die Leukocyten ausgeübte Wirkung dem Produkte der Neutralisierung des Opsonins zuzuschreiben ist. Wir können jedoch mittels Kapillarröhrchen untersuchen, welches Vermögen der Mischung nach erfolgter Reaktion zukommt.

Serum allein Tiefe: $2,2 \mathrm{~mm}$, Dichte: spärlich
Filtrat $>$
Beide miteinander vermengt $>4,5, \infty>>$

Es ist damit nachgewiesen, daß die Verbindung der opsonophilen Bestandteile mit dem Opsonin selbst die chemotropische Substanz darstellt. Freilich fehlt diesem Nachweis eine volle Beweiskräftigkeit, da die Kulturflüssigkeit schon selbst eine beträchtliche chemotaktische Tätigkeit aufweist, die zwar bei den Serumkulturen am deutlichsten hervortritt, jedoch auch bei Bouillonblutkulturen erkennbar ist. Solche Kulturflüssigkeiten sind infolge ihrer ursprünglichen Beschaffenheit und der darin erfolgenden Reaktionen sehr komplexer Natur; überdies muß ein Teil des in denselben vorhandenen Chemotropins ohne Zweifel auf die Mitwirkung der physiologischen Opsonine zurückgeführt werden, die sich in dem zur Beförderung der Kultur hinzugesetzten Blute befinden.

Es muß hierzu hervorgehoben werden, daß das frische opsonische Serum selbst ein höchst geringes chemotaktisches Vermögen aufweist; trotzdem findet man Sera, bei welchen dieses Vermögen ziemlich stark ist, sei es, daß Überbleibsel des durch die Wirkung des im Impfstoff enthaltenen Antigens gebildeten Chemotropins in demselben vorhanden sind, sei es, daß Elemente von anderer Beschaffenheit zufälligerweise auf- 
tretn, am wahrscheinlichsten sekundäre Antigene (Metantigene) vonden durch die Impfstoffe modifizierten Geweben geliefert.

7. Iber das ursprüngliche und das durch Kombination hervorgestellte Chemotropin.

Um die Versuche mit möglichst reinem Bakterienextrakt anzstellen, wurde der Bodensatz von Bouillonblutkulturen angevendet, den man zunächst durch Waschen von allem Kulturmairial reinigte, dann bei der einen Prüfung in Kochsalzlösung, beider anderen in destilliertem Wasser, in einer Menge, die etwa das vierfache Volumen des Niederschlages darstellte, aufschremmte. Die Aufschwemmung blieb durch 5 Tage, unter häuggem Schütteln, im Thermostaten. Während dieser Zeit schvillt die in dem Röhrchen mit destilliertem Wasser befindlicb Bakterienmasse an und fällt langsam zu Boden, worauf dieflüssigkeit eine gelbliche Farbe aufweist; in dem anderen Rörchen tritt keine sichtliche Veränderung auf.

Die Prüfung wird in der Weise vorgenommen, daß man nah genau ausgeführter Abzentrifugierung die Flüssigkeiten abipettiert und das mit destilliertem Wasser bereitete Extrakt durh Zusatz einer konzentrierten Kochsalzlösung isotonisch maht; ferner wird die Sterilität geprüft, die, wie bekannt, in auf küstlichem Nährboden kultivierten Pneumococcen im Laufe von 3-5 Tagen sich spontan herstellt, worauf opsoniches Serum in fleicher Menge zugetan wird.

Kapillarröhrchen mit in Kochsalzlösung bereitetem Extrakt:

Serum allein Tiefe: $0,3 \mathrm{~mm}$, Dichte: sehr spärlich
Extrakt allein
Mischung der beiden $\gg, 1,2,2$

Kapillarröhrchen mit in destilliertem Wasser bereitetem Excakt.

Serum allein Tiefe: $0,2 \mathrm{~mm}$, Dichte : sehr spärlich

Extrakt allein . $\quad 2,3$ \ spärlich

Mischung der beiden , 1,6, ,

Die Extraktion mit der Kochsalzlösung gibt in der Tat ein Rmzip ab, welches, mit dem Serum in Verbindung gebracht, eine vif ausgesprochenere chemotropische Wirkung ausübt. Auch 
hier ist jedoch das Extrakt schon selbst mit einem beträchtlichen chemotaktischen Vermögen ausgestattet; entweder, weil das andere, das ursprüngliche Chemotropin zum Teile noch beigemischt ist, oder weil der Umstand, daß die Mitwirkung des Serums in dem Kulturmaterial beseitigt wurde, es nicht hindert, daß das Extrakt nach subkutaner Injektion, von jedem weiteren Zusatz abgesehen, chemotropische Substanz erzeugt, indem es am Ende des Kapillarröhrchens mit den Körpersäften sich mischt. Demnach ist es an der Hand dieses Verfahrens nicht möglich, ein allein inaktives chemotropinerzeugendes Prinzip als solches nachzuweisen.

Unerwartet scheint auf den ersten Blick das Resultat, das man unter Anwendung von in destilliertem Wasser bereitetem Extrakte erzielt. Dasselbe besitzt schon allein ein beträchtliches chemotropisches Vermögen, welches höher ist als bei dem mittels Kochsalzlösung gewonnenen Extrakte. Das Interessante dabei ist aber, daß die Beimengung von opsonischem Serum dieses ursprüngliche Vermögen nicht erhöht, sondern vielmehr um die Hälfte verringert, nicht anders, als hätte das hinzugesetzte Serum nur einfach als ein Verdünnungsmittel gewirkt. Es bilden sich also aus dem Bakterium zweierlei Chemotropine, das durch die Kombinierung der opsonophilen Substanz mit dem Serum entstehende, und das ursprüngliche, ohne Mitwirkung des Serums vorkommende Ghemotropin.

Diese zweite Form von Chemotropin trägt zur Aufklärung einer öfters besprochenen Frage in der Opsoninlehre bedeutend bei; es ist das die Frage nach der spontanen Phagocytose. Bekanntlich gibt es eine Anzahl Keime, die nach Wright der Gruppe der Diphtherie- und der Xerosebakterien angehören, welche von den Leukocyten, gleichviel ob Serum zugesetat wird oder nicht, phagocytiert werden. Ferner hat Löhlein nachgewiesen, daß Bakterien, wenn man nur die dazu erforderliche Zeit abwartet, selbst unter einfacher Anwendung von Kochsalzlösung phagocytiert werden; dieser Forscher führt Vergleichungsproben mit aktiver Sera an, aus welchen hervorgeht, daß, wenn das Serum in den ersten Phasen des Kontaktes im Vorteile zu sein scheint, dagegen in den späteren Perioden, 
z. B. beim Kolibakterium nach 45 Minuten, der Index im Serum und im Wasser auf gleicher Höhe stehen.

Löhlein nimmt das Vorhandensein eines mit opsonischem Vermögen ausgestatteten, in den Leukocyten enthaltenen Bestandteiles an, welchen die Leukocyten im Laufe der Probe nach und nach abgeben. Diese Vermutung mag wohl begründet sein, da man wirklich sieht, daß der Keim, welcher in der ersten Periode aufgenommen wird, und dessen opsonophile Zone, wie wir wissen, zum Teil noch erhalten ist, zuletzt innerhalb der Leukocyten eine vollständige Auflösung erfährt. Dennoch ist uns heutzutage eine direktere Erklärung möglich, nämlich die allmähliche Diffusion dieses im Bakterium vorgebildeten Chemotropins.

Später werden einmal wahrscheinlich die Beziehungen zwișchen beiden Produkten aufgeklärt werden; ihre Mannigfaltigkeit darf uns nicht überraschen, da ja bekannt ist, wie viele physikalische und chemische Agenten die chemotaktische Tätigkeit $\mathrm{zu}$ entwickeln imstande sind, und $\mathrm{zwar}$ vielleicht infolge der verschiedenen Empfindlichkeit und der verschiedenen physiologischen Bedürfnisse des kleinen, hierbei beeinflußten Organismus. Bei den uns vorliegenden Abarten bemerken wir eine wesentliche Verschiedenheit: während nämlich die opsonischen Chemotropine als die Erzeugnisse spezifischer Reaktionen auftreten, weisen die vorgebildeten Chemotropine einen allgemeinen Charakter auf.

In bezug auf die Hervorrufung der phagocytären Wirkung ist dieser allgemeine Charakter allen Chemotropinsorten, einmal gebildeten, gemein. Hier schließt sich die Frage der hyperleukocytären Therapie und der Polyvaccination an; welcher Ausdehnung diese nicht spezifische Form der Schutzimpfung fähig ist, könnte ich in ausgezeichnetem Umfang schon zeigen, indem ich eben Produkte des Pneumococcus auf natürlichen Medien benutzte; wir wollen später die Frage weiter erörtern durch die Beobachtung der Wirkungen des Chemotropins auf den lebendigen Organismus.

In diesem Kombinationschemotropin könnte man die Metschnik offs-Stimuline erkennen; aber in einer unter der 
Leitung dieses Forschers ausgeführten Arbeit spricht Sleeswijk, nur in hypothetischer Weise, die Meinung aus, daß das Opsonin aus zwei Elementen zusammengesetzt sei, von denen das eine auf den Keim, das andere auf den Leukocyt seine Wirkung ausübt.

\section{Absorption des Chemotropins von seiten der Leukocyten.}

Das Chemotropin, das Hauptreagens auf dem Gebiete der folgenden Untersuchungen, wurde mit frisch aus dem Tiere gewonnenem antipneumonischen Serum hergestellt, welches mit dem fünffachen Volumen Bakterienbodensatz vermengt und durch 45-60 Minuten unter häufigem Schütteln im Brutschrank erhalten wurde. Diese Methode kann einige Vervollkommnung erfahren, und zwar sowohl durch Berücksichtigung des Vermögens des angewandten Serums, als durch die Wahl des bakteriellen reagierenden Materials. Durch solche Maßregeln wird einzelnen in der Wirksamkeit des hervorgebrachten Produktes auftretenden Unregelmäßigkeiten vorgebeugt.

Um die zu solchen Prüfungen absolut erforderliche Sterilisierung zu erzielen, wurde die Filtrierung durch poröse Tonfilter und die halbstündige Sterilisierung durch Erhitzung auf $58^{\circ}$ versuchsweise angewendet; und zwar wurde letztere zwecks Vergleichung der Resultate auch an der filtrierten Flüssigkeit vorgenommen.

Natürliches Filtrat Tiefe: $5,0 \mathrm{~mm}$, Dichte: sehr stark

Filtrat bei $58^{\circ}$ »3,2,$\quad$ stark.

Die mittels Tonfilter ausgeführte Filtrierung liefert also ein gutes Chemotropin; die mäßige Erwärmung setzt sein Vermögen ungefähr um die Hälfte herab. Wright hatte diesbezüglich bemerkt, daß die Temperatur von $60^{\circ}$ auf das normale Opsonin allein im Gegensatze zu dem Immunopsonin zerstörend wirkt, während eine solche Wirkung auf die Verbindung des Opsonins mit dem Bakterium nicht ausgeübt wird. Wie es in der Tat nachgewiesen wurde, daß diese Temperatur den Immunopsoninen gegenüber nicht harmlos ist, so ergibt sich nun auch, daß dies ebenfalls bei dem Produkt ihrer Kombinierung der Fall ist. 
Bisher wurde die Rolle des Bakteriums bei der Phagocytose erörtert. Was nun die Leukocyten anbelangt, müssen wir uns zunächst die Frage stellen, ob die Reizwirkung, welche das Chemotropin auf die Leukocyten ausübt, dem allgemeinen. Prinzip des Verbrauches der Substanz und der daraus hervorgehenden Abnahme in der Flüssigkeit gehorcht.

Es wird eine Mischung von 1,0 ccm Chemotropin und $0,5 \mathrm{ccm}$ von der Flüssigkeit befreiten Leukocyten hergestellt, die man 5 Stunden lang im Ofen stehen läßt, während der Rest durch 48 Stunden der Zimmertemperatur ausgesetzt wird, worauf man die abzentrifugierte Flüssigkeit prüft.

Natürliches Chemotropin Tiefe: 5,4 mm, Dichte: stark

Erschöpftes $>2,8$ > mäBig.

Die Wirkung des Chemotropins auf die Leukocyten hängt demnach mit der Absorption desselben zusammen. Aus mehreren Gründen bleibt es ausgeschlossen, daß die nach dem Kontakte auftretende Verringerung dem Vorhandensein von hemmenden Substanzen, die von den Leukocyten selbst hervorgebracht werden, zuzuschreiben sei; in der Kochsalzlösung treten solche nicht auf, und in den Kapillarröhrchen gestatten die zuerst eingedrungenen Leukocyten ein immer tieferes Eindringen.

\section{Hemmung der Leukocyten durch Sättigung.}

Es ist bekannt, daß die Phagocytose mit dem allgemeinen Ernährungsprozesse in engem Zusammenhange steht. $0 \mathrm{~b}$ nun das Chemotropin ein Reizmittel zur Aufsuchung des passenden Nahrungsstoffes bildet, oder ob es selbst ein Nahrungsstoff ist, es ist jedenfalls interessant zu erforschen, wie die Leukocyten nach fortgesetzter Absorption sich schließlich verhalten.

Man vermengt $0,25 \mathrm{ccm}$ konzentriertes Chemotropin mit 0,05 Leukocyten und läßt die Röhrchen durch immer länger werdende Zeiträume im Ofen stehen. Am Schlusse jeder dieser Perioden werden die Leukocyten des einen Röhrchens durch wiederholtes Waschen von dem Chemotropin befreit, aus dem anderen Röhrchen dagegen wird das Chemotropin nicht entfernt; man prüft das phagocytäre Vermögen der beiden, indem 
man eine gleiche Dosis von opsonischem Serum und von Bakterien hinzusetzt und beide durch Hinzufügen von Kochsalzlösung auf das gleiche Volumen bringt. Die zur Kontrolle dienenden Leukocyten bleiben eine gleiche Zeitperiode hindurch in normalem Kaninchenserum, in einzelnen Prïfungen vergleichsweise in Kochsalzlösung. Bei der nach 24 stündigem Kontakt vorgenommenen Prüfung wird ein Teil während der Nacht der Zimmertemperatur bei $25^{\circ}$ ausgesetzt.

\begin{tabular}{|c|c|c|c|c|c|}
\hline \multicolumn{3}{|c|}{ are Prüfung } & g bei Gegenwart des $C$ & Chemotropins & Index 15 \\
\hline & 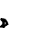 & $\triangleright$ & mit Normalserum & & s \\
\hline Nach & & Stunden & $\int$ nach Entfernung des & s Chemot & » \\
\hline Nacn & & Stunden & ( bei Gegenwart & $x>$ & $>$ \\
\hline$>$ & 3 & $D$ & mit Normalserum & & 》 \\
\hline D & 3 & $\triangleright$ & $\gg$ Koch & & » \\
\hline$>$ & & & ( nach Er & s Chemot & $\triangleright$ \\
\hline$>$ & 2 & & ei Gege & , & \\
\hline D & 24 & , & mit Normalserum & & $\triangleright$ \\
\hline
\end{tabular}

Bei den unter Entfernung des Chemotropins in der ersten Periode vorgenommenen Prüfungen erscheint der Leukocyt nicht beeinflußt, ja seine Tätigkeit erscheint bei der Vergleichung mit der im Serum aufgeschwemmten Kontrolle erhöht. Später sind seine phagocytären Eigenschaften beträchtlich verringert: dem allgemeinen Gesetze gemäß tritt der absorbierten Substanz gegenüber die Sättigung auf.

Das Auftreten und die Intensität der Erscheinung hängen auch mit der Konzentration des Chemotropins, wohl aber auch mit Überresten von bei dem Herstellungsprozesse frei gebliebenem Opsonin zusammen. In anderen Fällen, bei Seren von Schafen und Hunden, scheint das Auftreten von toxischen Substanzen mitzuspielen, es wurde nämlich durch diese Sera selbst die endotoxische Zone des Pneumococcus angegriffen.

Wir werden bald die Bedeutung der Versuche besprechen, bei welchen das Chemotropin während der Prüfung der Phagocytose nicht entfernt war. Inzwischen müssen wir hervorheben, daß die Leukocyten infolge des Aufenthalts in Kochsalzlösung eine starke Herabsetzung ihrer Tätigkeit erfahren, sodaß diese Lösung nicht, wie einzelne Forscher betont hatten, als eine 
gleichzeitige Kontrollflüssigkeit anzusehen ist. Diese Veränderung geht auch aus dem Umstande hervor, daß die unter Anwendung der Kochsalzlösung allein ausgeführten Prüfungen der Phagocytose, wegen der verringerten Färbbarkeit, sehr unbestimmte Präparate liefern.

$\mathrm{DaB}$ es sich bei der Hemmung der Leukocyten nur um ein zeitweiliges Hindernis handelt, nicht aber um eine eigentliche toxische Wirkung, wird durch mehrere Tatsachen bewiesen. Unter dem Mikroskop weisen diese Leukocyten nach längere Zeit fortgesetztem Kontakt mit Chemotropin eine ganz normale Struktur auf, und zwar selbst zu einer Zeit, da die unter densèlben befindlichen Erythrocyten, wie im Hundeblut, infolge der Lysis fast gänzlich verschwunden sind.

Der absolut entscheidende Beweis kann auf biologischem Wege erlangt werden, nämlich dadurch, daß man erforscht, ob die funktionelle Tätigkeit durch die Ruhe hergestellt werden kann. Die nach den letzten Angaben der vorhergehenden Tabelle inaktiv erscheinenden Leukocyten werden zuerst gewaschen, dann in frischem, normalem Kaninchenserum, durch Zeitperioden von verschiedener Dauer im Brutschrank gelassen, hernach zur Anstellung der Wrightschen Probe mit Leukocyten vermengt, die durch einen gleichen Zeitraum im Kontakte mit Normalserum geblieben sind.

Durch 4 Stunden gesättigt; (mit Chemotropin nach $20^{\prime} \quad 6$, nach $30^{\prime} \quad 9$ unmittelbare Prüfung $\begin{cases}\text { gewaschen } & , 20^{\prime} 8, \geqslant 30^{\prime} 56 \\ \text { Kontrolle } & , 20^{\prime} 44,30^{\prime} 63\end{cases}$

Durch 20 Stunden gesättigt; 3 Stunden 58 wiederhergestellt während $\{24>$ (18 bei Zimmertemperatur) 110

Die funktionelle Wiederherstellung der gehemmten Leukocyten ist demnach, nach einiger Zeit der Ruhe, eine vollständige. Die erforderliche Zeit ist beträchtlich, wenn die Sättigung eine hohe Stufe erreicht hatte; bei niedrigeren Stufen ist nur während der ersten Periode der Wrightschen Probe eine gewisse Trägheit bemerkbar, wird aber die Probe verlängert, so steigt die Tätigkeit wieder schnell beinahe auf die Höhe der Wirksamkeit normaler Leukocyten. 
Gelegentlich dieses Inaktivierungsverfahrens muß erwähnt werden, daß wir bei der mehrmals vorgenommenen Gewinnung von Leukocyten mittels Aleuronat aus der Pleura- und Peritonealhöhle stets bemerkt haben, daß die Aktivität dieser Leukocyten unregelmäßige Schwankungen erfuhr, und daß in einzelnen Fällen die älteren Leukocyten aktiver waren, als die frisch gewonnenen. Diese Erscheinung mag wohl auch in diesem Falle mit der Sättigung zusammenhängen, die infolge der Absorption des als ein Chemotropin wirkenden Aleuronats auftritt.

Eine Anzahl von meinen Versuchen waren ferner darauf gerichtet, $\mathrm{zu}$ erforschen, ob die vorhergehende Absorption von Chemotropin von seiten der Leukocyten die Empfindlichkeit derselben für die folgenden Prüfungen in irgend welchem Maße regelmäßig modifiziert; die Ergebnisse waren aber nicht ganz miteinander im Einklang, und zwar namentlich weil infolge der ziemlich langen Dauer der Versuche spontane Schwankungen in der Tätigkeit der angewendeten Leukocyten auftreten. Günstigere Verhältnisse wird man bei der Prüfung des Chemotropins an dem lebenden Organismus haben; es wird dann also möglich werden, festzustellen, ob die rascher erfolgende Gegenwirkung einem neuen pathogenen Material gegenüber, der wir bei schon einmal immunisierten Individuen begegnen, auf eine Anpassung der Leukocyten in dem von Metschnikoff aufgeführten Sinne, oder auf deren Stomose gegen die paralysierenden Toxine, oder aber auf die schnellere Organisierung der Schutzvorrichtungen von seiten der Säfte zurückzuführen ist.

Das bisher über das Verhalten der Leukocyten dem Chemotropin gegenüber Erörterte führt eher zur Annahme, daß diese Substanz eine den Nahrungsstoffen nahestehende Verbindung ist. Was aus den Nahrungsstoffen wird, nachdem sie durch die Magen- und Darmschleimhaut durchgedrungen sind, ist uns völlig unbekannt. Die an Hand der vorliegenden Beobachtungen erzielten Resultate scheinen uns zu einer Erklärung behilflich $\mathrm{zu}$ sein, wenn wir bedenken, daß wir in den Opsoninen Verbindungen vor uns haben, die im Normalblut verbreitet sind, und daß die Verdauung eben von Leukocytose begleitet wird. In der Bestrebung, die durch die Immunitäts- 
lehre festgestellten Prinzipien für die allgemeine Biologie $\mathrm{zu}$ verwerten, haben wir es nun unternommen, die gleichen Anschauungen und die gleichen Verfahren wie bei dem Studium des bakteriellen Chemotropins auch bei der Beobachtung der verschiedenen Gruppen der Nährungsprodukte anzuwenden.

Vorläufig wollen wir nur auf die Bedeutung hinweisen, die die bisher erzielten Resultate auch für die allgemeinen Immunitätstheorien besitzen. Zur Ergänzung der Lehre von der Stomose in bezug auf die celluläre Immunität habe ich für die Produktion der Immunsubstanz der Säfte das Prinzip zugrunde gelegt, daß es sich hier nicht etwa um eine Beteiligung. und Entfernung der Rezeptoren der Gewebezelle handelt, sondern um eine Arbeitshyperplasie bestimmter Komplexe des Blutplasmas, welche die physiologische Rolle chemischer Träger (Translatoren) der Elemente des inneren Stoffwechsels spielen, das heißt, daß sie mit den letzteren mehr oder weniger enge Verbindungen bilden, welche entweder gelöst werden können, wie das bei Hämoglobin dem $\mathrm{O}_{2}$ gegenüber der Fall ist, oder fest werden, wie bei dem neutralisierten Antikörper, in welchem Falle diese Komplexe, dem Grundprinzip der Stomose entsprechend, als solche verloren gehen.

Das Blutplasma soll nach den durch die biologischen Arbeiten der neuen Richtung gewonnenen Anschauungen nicht etwa als eine sich passiv verhaltende, nur auf mechanischem Wege beförderte Mischung von Nahrungsstoffen, sondern vielmehr wesentlich als ein Plasma von cellulärer Beschaffenheit wie eine riesige Amöbe betrachtet werden, welchem biologischchemische Funktionen zufallen, insofern es an der Anordnung und teils an der Bearbeitung des zwischen den einzelnen cellulären Gebieten bestehenden Verkehrs aktiv teilnimmt, während es bezüglich seines Entstehens von den hämatopoietischen Organen abhängt. Was die Immunität betrifft, geht in der Tat aus den gegenwärtigen Forschungen immer deutlicher hervor, daß die Erzeugung der Antikörper als eine ausschließliche Funktion des Blutes anzusehen ist.

Nun geht aus unseren Untersuchungen eben hervor, daß die im Blute befindlichen Opsonine als kombinierende Träger 
wirksam sind, indem sie die opsonophile Substanz, die allein dieses Übertrittes nicht fähig sein würde, in das Innere der Leukocyten befördern. Daß ferner gleichzeitig Substanzen vorhanden sind, welche auch ohne diese Mitwirkung in die Leukocyten dringen, nämlich die ürsprünglichen Chemotropine, mag zur Erläuterung des Prinzips führen, welches einer bestimmten Substanz den Charakter eines Antigens verleiht oder abspricht, je nachdem sie translatorfähig im Blutplasma ist oder nicht. Eine solche Erklärung in der Fähigkeit zu suchen, eigentliche spezifische Verbindungen mit den Geweberezeptoren einzugehen oder nicht, scheint nicht zutreffend zu sein, da solche Verbindungen, vielerlei Proben zufolge, in der ausgesprochensten Weise bei den beiden Kategorien auftreten.

\section{Hemmung der Leukocyten durch Desorientierung.}

Aus der schon im vorigen Kapitel benutzten Tabelle ist ersichtlich, daß die Phagocytose auch in der ersten Periode noch eine Hemmung erfährt, welche auf die Gegenwart des zur phagocytären Prüfung hinzugefügten Chemotropins zurückzuführen ist, denn die gewaschenen Leukocyten nehmen ihre frühere Empfindlichkeit wieder an, weil sie die zur Inaktivierung durch Sättigung erforderliche Menge von Chemotropin noch nicht aufgenommen haben.

Diese Erscheinung läßt sich leicht erklären, faßt man nur den Mechanismus des Zustandekommens der Chemotaxis recht ins Auge, welcher auf der verschiedenen Konzentration des. aktiven Prinzips in der Umgebung des beweglichen Lebewesens beruht. Wird dem sich um das Bakterium herum gebildeten Chemotropin noch anderes Chemotropin künstlich beigefügt, so wird diese Verschiedenheit in der Konzentration verringert und das indifferente Gleichgewicht beinahe erreicht. So läßt z. B. ein Zusatz von $10 \%$ Chemotropin zu den schon bestehenden Konzentrationen von $1 \%$ um den Leukocyt und $10 \%$ um das Bakterium, die Differenz von $1 / 10$ auf fast ${ }^{1 / 2}$ sinken. Die Leukocyten, die so von allen Seiten gereizt werden, müssen desorientiert erscheinen. Dennoch besteht eine gewisse Differenz noch immer, und daher bei stark opsonischen Seren und sehr 
empfindlichen Leukocyten, wie es bei Hundeserum der Fall war, wird diese Hemmung eine immer weniger ausgesprochene.

Es ist ziemlich schwer, diese Hemmung der Phagocytose auf den beiden hier angeführten Wegen, dem Sättigungs- und Desorientierungsverfahren, innerhalb des Organismus hervorzurufen, da es hierzu erforderlich ist, daß sehr stark konzentrierte Reagenzien mitwirken und daß die reagierende Masse sich wenig erneuert. Günstigere Verhältnisse scheinen bei den Exsudaten vorzuliegen, womit wir zu einer weiteren Kategorie von Substanzen übergehen, die ebenfalls neuerdings nachgewiesen wurden und mit den Opsoninen in Beziehung stehen, nämlich zu den Bailschen Aggressinen.

Der Kernpunkt des von diesem Forscher verfochtenen Prinzips liegt nicht in dem schon früher, und zwar auch von mir an der Hand spezieller Untersuchungen beobachteten Auftreten einer vorbereitenden Wirkung, sondern darin, daß der genannte Forscher die Agenten als selbständige Produkte in bezug auf die Phagocytose auffaßt und dabei besonders betont, daß dieselben nicht toxisch sind und innerhalb des Organismus erzeugt werden. Eine zweite Schule dagegen, an deren Spitze Wassermann und Gitron stehen, betrachtet dieselben als Bestandteile eines aus den Kulturen stammenden Toxins.

Als Aggressine wurden freilich eine Menge verschiedener Substanzen betrachtet und angesprochen. Unsere Untersuchungen haben mannigfaltige Produkte, welche auf die Phagocytose hemmend wirken, zu unterscheiden gelehrt, welche folgendermaßen eingeteilt werden können: a) nach der Toxizität, in Substanzen, die nicht toxisch sind (Opsonin, Opsonophile, Chemotropin) und in toxische Substanzen (Endotoxin); b) nach der Entstehung, und zwar bakteriellen Ursprungs (opsonophile Substanzen, Endotoxin) bezw. vom Organismus erzeugt oder sich am besten innerhalb desselben entwickeln (Opsonin, Chemotropin, Endotoxin, die in den Säften leichter löslich sind); c) nach dem Sitz der Wirkung, nämlich auf das Bakterium (Saturation durch Einbuße an Rezeptoren), auf das Opsonin (Neutralisierung von seiten der opsonophilen Substanz), auf die Leukocyten 
(Vergiftung durch Endotoxin, Hemmung infolge der Sättigung oder der Desorientierung); d) nach der Spezifität, und zwar bei den einen in ausgesprochener Weise (Opsonin, Opsonophile), bei den anderen nur in beschränkter Weise (Chemotropin, Endotoxin).

Es geht wieder aus diesen Ergebnissen hervor, daß, dank dem Fortschritte unserer analytischen Verfahren, selbst die entgegengesetztesten Ansichten, wenn sie auf streng experimentellen Grundlagen beruhen, schließlich alle nebeneinander in das weite Gebiet der biologischen Erscheinungen eingereiht werden können.

\section{Schlußbetrachtung.}

Folgendes Schema mag wohl das Verständnis der durch vorliegende Untersuchungen bezüglich des vom Pneumococcenopsonin gebildeten Chemotropins festgestellten Tatsachen erleichtern.

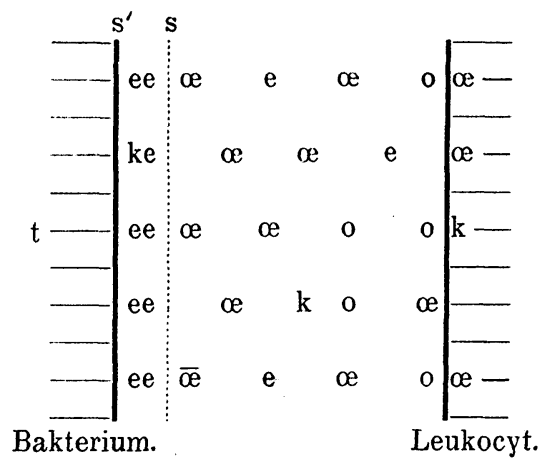

Die die Phagocytose befördernde Wirkung des Opsonins ist auf die Entstehung einer positiv chemotropischen Substanz œ zurückzuführen, welche aus der Verbindung des Opsonins o mit einem opsonophilen Komplexe e des Bakteriums hervorgeht.

Der Pneumococcus scheint mit einer beträchtlichen Anzahl solcher opsonophilen Komplexe ausgestattet zu sein, welche in verschiedenen aufeinanderfolgenden Phasen sich mit dem Opsonin verbinden, als ob erstere eine in Schichten gelagerte Hülle an der Peripherie bilden würden $\left(\mathrm{s}^{\prime}-\mathrm{s}\right)$. 
Sowohl die Verbindung des Opsonins o mit der opsonophilen Substanz e, als auch die Lösung und die Entfernung des erzeugten Chemotropins $œ$ gehen mit der größten Schnelligkeit vor sich, so daß der gewaschene Keim die Sensibilisierung, die derselbe durch den früheren Kontakt mit dem Opsonin gewonnen hatte, bald einbüßt (Grenze s).

Die Wiederholung der Kombinierung von e mit $o$ und der Entfernung des Verbindungproduktes œ führt nahe zur Erschöpfung der opsonophilen Substanzen e (Grenz s'); hier weist das Opsonin eine geringe Wirksamkeit dem Bakterium gegenüber auf, und es tritt dabei die Form der cellulären Unempfindlichkeit oder Stomose infolge der Einbuße an spezifischen kombinierenden Komplexen auf. Dieselben Keime jedoch erfahren durch den Aufenthalt in Normalserum eine vollständige Wiederherstellung und weisen dem Opsonin gegenüber eine normale Empfindlichkeit auf.

$\mathrm{Da}$, infolge der Abschwächung, die Bildung echter Opsonoide schwerlich zustande kommt, so läßt sich hier die andere Form der Stomose nicht nachweisen, welche durch die Kombinierung der opsonophilen Substanz e mit dem Opsonoid ô unter Sättigung der verwandten Komplexe, aber ohne Lostrennung der gebildeten Verbindung ôe entsteht.

Die Opsonophilen e trennen sich auch von selbst von dem Keime in der umgebenden Flüssigkeit und vermögen dann ebensogut das Opsonin o unter Erzeugung von Chemotropin $œ \mathrm{zu}$ neutralisieren, obwohl diese Neutralisierung mit geringerer Avidität stattfindet, als von Seite der noch an dem Keime haftenden opsonophilen Substanzen.

Neben dem durch die Verbindung mit Opsonin entstehenden Chemotropin œ scheidet der Keim noch ein präexistierendes Chemotropin $\mathrm{k}$ aus, das in demselben als solches präformiert vorhanden war, und zwar ohne jede Mitwirkung des Opsonins; diese Erscheinung kann die spontane Phagocytose erklären.

So lassen sich im Bakterium eine äußere Zone $\left(s^{\prime}-s\right)$, die sich als opsonophil und durchaus atoxisch erweist, und eine innere Zone $\left(t-s^{\prime}\right)$ unterscheiden, welch letztere mit toxischen Eigenschaften ausgestattet ist (Endotoxin, welches schwerlich 
durch die Scheidewand $\mathbf{s}^{\prime}$ diffundiert) und durch eine andere Substanz neutralisiert wird, die von dem Opsonin verschieden ist. Das Opsonin erscheint demnach als ein partielles Lysin, ein Esolysin, während die eigentlichen Bakteriolysine auch ein Endolysin enthalten sollten.

Die phagocitäre Reizwirkung, welche das Chemotropin auf die Leukocyten ausübt, hängt mit der Absorption und mit dem Verbrauch desselben zusammen. Auf eine fortgesetzte Absorption folgt eine Hemmung durch eine Sättigung, welche die Leukocyten außerstand setzt, den opsonisierten Keimen gegenüber zu reagieren; dieselben nehmen jedoch, nach einiger Zeit der Ruhe, ihre frühere phagocytäre Tätigkeit wieder auf.

Eine weitere Form der Hemmung wird bei den Leukocyten durch Desorientierung hervorgerufen, wenn nämlich das Chemotropin in der umgebenden Flüssigkeit stark konzentriert ist, wodurch die Differenz zwischen der Umgebung des Leukocyts und des Keims, auf der die chemotropische Wirkung beruht, verringert wird.

Im Laufe der Untersuchung sind Tatsachen beobachtet worden, welche das Wesen der Resorption der Nahrungsstoffe, wie auch der Aggressine, des cellulären Widerstandes der Leukocyten und der Bakterien, sowie der polyvalenten Schutzimpfung und die Entstehung der Immunkörper aufzuklären geeignet sein durften.

Die Umwandlung einer an sich wenig oder gar nicht chemotropischen Substanz in ein aktives Chemotropin kann zur Erkennung sowohl von Antigen, bei Gegenwart von Antikörpern, als von Antikörpern, in Gegenwart von Antigen, benutzt werden, und die Grundlage zu einem neuen der Komplementablenkung und der Präcipitinreaktion analoges Verfahren abgeben, welches zum Nachweis einer besonderen Kategorie von Immunitätsprodukten dienen kann. 


\section{Literatur.}

Vorgetragen in der Sitzung vom 12. September 1907 der Akad. d. Physiokritiker zu Siena.

Denys et Leclef, Sur le mécanisme de l'immunité chez le lapin vacciné contre le streptococque pyogène. (La Cellule, Bd. XI, S. 177, 1895.)

Centanni, Rapporti di affinità dello pneumococco e del suo siero immunizzante. Accad. med. Ferrara, 11 genn. 1902.

Wright and Douglas, An experimental investigation of the rôle of the blood fluids in connection with phagocytosis (Proceed. of the royal Soc. London, 29 July 1903).

Neufeld und Rimpau, Über die Antikörper des Streptococcenund Pneumococcenimmunserums (Deutsch. med. Wochenschr., Nr. 40, 1904).

Centanni, Über die Veränderungen der biologischen Vermögen des Blutes nach der Entziehungsbehandlung bei der Pneumonie (Accad. d. Fisiocritici, 27 apr. 1904; erscheint in Zeitschr. f. klin. Medizin).

Centanni, Sul valore immunizzante dell' infiltrato locale nelle malattie infettive (Gazz. d. Osped., Nr. 106, 1898).

$\mathrm{Bulloch}$ and Atkin, Experiments on the nature of the opsonic action of the blood serum (Proceed. roy. Soc.; Vol. LXXIV, P. 379, 1905).

Dean, An experimental enquiry into the nature of the substance in serum which influences phagocytosis (Proceed. roy. Soc., Vol. LXXVI, P. 506, 1905).

Hektoen and Rüdinger, Studies in phagocytosis (The Journ. of inf. Diseas., Vol. II, P. 128, 1905).

Leishman, Some experiments in connection with estimulins s (Trans. path. soc. London, Vol. LVI, P. 344, 1905).

Bail, Untersuchungen über Typhus- und Choleraimmunität (Arch. f. Hyg., Bd. LII, S. 272, 1905).

Mancini, I poteri biologici del sangue nella polmonite fibrinosa (Accad. d. Fisiocritici Siena, 13 lug. 1907).

Mac Fadyen, Über das Pneumotoxin (Centralbl. f. Bakt., Bd. XLIII, S. 30, 1906).

Centanni, Grundtheorien über die Immunität: der «Stomose» für die histogene (Deutsch. med. Woch., Nr. 44 u. 45, 1893; Policlinico, 1896; Rif. medica 1897 e 1902); der «chemischen Translatoren für die humorale (Inaug.-Dișsert., Siena 1906).

Sauerbeck, Neue Tatsachen und Theorien in der Immunitätsforschung (Lubarsch-0stertags Ergebn. 1906, I. Abteil., S. 690, mit ausführlicher Literatur über die Opsonine und Aggressine).

Hoppe-Seyler's Zeitschrift f. physiol. Chemie. LV. 
Eisenberg, Über die Anpassung der Bakterien an die Abwehr:kräfte des infizierten Organismus (Centralbl. f. Bakt., Bd. XXXIV, S. 7399, 1903; ibid., Bd. XLV, S. 44, 1907).

Wass ermann und Gitron, Zur Frage der Bildung von bakteriellem Angriffstoffen im lebenden Organismus (Deutsch. med. Woch., Nr. 28, 1905)).

Löhlein, Sur la phagocytose (in vitro> des microbes pathogèness (Ann. Pasteur, 1905, S. 647).

Sleeswijk, Contribution à l'étude des opsonines (Ann. Pasteur., Nr. 12, 1907). 